\title{
Structure and Properties of Selected Cemented Carbides and Cermets Covered with TiN/(Ti,Al,Si)N/TiN Coatings Obtained by the Cathodic Arc Evaporation Process
}

\author{
Leszek A. Dobrzañski*, Klaudiusz Golombek \\ Division of Materials Processing Technology and Computer Techniques in Materials Science, \\ Institute of Engineering Materials and Biomaterials, Silesian University of Technology, \\ 44-100 Gliwice, ul. Konarskiego 18A, Poland
}

Received: November 23, 2003; Revised: February 1, 2005

\begin{abstract}
This study presents the results of microstructural examinations, mechanical tests and service performance tests carried out on thin TiN/(Ti,Al,Si)N/TiN wear resistance coatings obtained by the CAE process on cermet and cemented carbide substrates. Microstructural examinations of the applied coatings and the substrate were made with an OPTON DSM 940 SEM and a LEICA MEF4A light microscope. Adhesion of the coatings on cemented carbides and cermets was measured using the scratch test. The cutting properties of the materials were determined from service tests in which continuous machining of C45E steel was carried out. The hardness of the substrate and the microhardness of the coatings were determined with a DUH 202 SHIMADZU ultra microhardness tester with a load of $70 \mathrm{mN}$. Roughness tests were also carried out before applying the coatings and after the PVD process. Cutting tests confirmed the advantages of the TiN/(Ti,Al,Si)N/TiN type coatings obtained using the PVD method in the CAE mode on cemented carbides and cermets, as a material that undergoes very low abrasive, thermal and adhesion wear. These coatings extend tool life compared to commercially available uncoated tools with single and multi-layer coatings deposited using PVD/CVD methods.
\end{abstract}

Keywords: PVD coatings, cermets, cemented carbides, cutting ability test

\section{Introduction}

The increased pace of development in manufacturing technology leads to a corresponding increase in requirements regarding working properties of current sintered tool materials. Deposition of hard wear resistance coatings based on carbides, nitrides, or transition metal oxides feature one of the fastest developing directions of research, stimulated by growth in service requirements of machines and equipment, generating improvements in sintered tool materials (sintered high speed steels, cemented carbides, cermets, ceramics). The wide choice of coatings available nowadays and technologies for their deposition is the result of the growth in the current demand for state-of-the-art surface modification methods. There has been increased interest in coatings having a combination of properties like resistance to tribological wear and corrosion. Tools covered with coatings based on carbides, borides, nitrides, and oxides can be used under more demanding service conditions (temperature, load, etc.). Moreover, the multilayer and multicomponent coatings developed recently enable control of the properties of the entire coating as well as that of the transition layer, ensuring thereby good adhesion, compensation of internal stresses, and transmission of external loads. Tools with such coatings have significantly extended service life compared to uncoated tools or those coated with simple coatings based on mononitrides or carbonitrides. These coatings also exhibit improved tribological contact in the tool-chip-machined material contact zone, and protection of the tool edge from oxidation and extensive overheating. Many aspects pertaining to the formation of coatings, including the effect of process conditions on their properties still remain unexplained in spite of the enormous interest at many industrial centres and research laboratories. Moreover, each combination of substrate material - coating type - deposition method, calls for the determination of properties of the coated material and the definition of a range of potential applications. Research in this area is concentrated on finding new composite coatings, both multicomponent and multilayer ones, and on studying the effect of adding new elements to coatings that have been used for many years, like silicon or vanadium to TiAlN ${ }^{1-5}$.

Cemented carbides coated with a composite multilayer (III generation) coating of $\mathrm{TiN} /(\mathrm{Ti}, \mathrm{Al}, \mathrm{Si}) \mathrm{N} / \mathrm{TiN}$ by the PVD method in the cathode arc evaporation (CAE) mode were studied in this investigation. The coated carbides were compared with commercially available uncoated tool materials and those coated by the PVD and CVD processes with single and multilayer wear resistant coatings.

\section{Experiments}

Investigations were carried out with uncoated and coated cemented carbides and cermets. The PVD method in the CAE mode was used to coat the cemented carbides and cermets with wear resistant $\mathrm{TiN} /(\mathrm{Ti}, \mathrm{Al}, \mathrm{Si}) \mathrm{N} / \mathrm{TiN}$ coatings. The following parameters were used to deposit the coatings: substrate polarisation - $200 \mathrm{~V}$, substrate temperature $550{ }^{\circ} \mathrm{C}$, pressure in the chamber $0.2 \mathrm{~Pa}$. Commercially available cemented carbides and cermets used for similar applications, according to the ISO classification, were coated using both the PVD or CVD processes, for comparison. Specifications of the materials studied in this investigation are presented in Table 1.

Evaluation of phase composition of the coatings was carried out with a DRON 2.0 X-ray diffractometer, using filtered cobalt rays, voltage of $40 \mathrm{kV}$ and heater current of $20 \mathrm{~mA}$. Measurements were made with $2 \theta$ angle in the range $30-115^{\circ}$.

Roughness measurements on the coatings and the substrates were carried out in two orthogonal directions with a Taylor-Hobson Sutronic3+ device. According to Polish Standard PN EN ISO 4287, the $\mathrm{R}_{\mathrm{a}}$ parameter was assumed to describe surface roughness. 
Table 1. Specification of the investigated materials.

\begin{tabular}{|c|c|c|c|c|}
\hline Designation & $\begin{array}{l}\text { Material } \\
\text { type }\end{array}$ & Coating & $\begin{array}{c}\text { Coating } \\
\text { thickness, } \\
(\mu \mathrm{m})\end{array}$ & $\begin{array}{c}\text { Process } \\
\text { type }\end{array}$ \\
\hline W1 & $\begin{array}{l}\text { Cemented } \\
\text { carbide }\end{array}$ & - & - & - \\
\hline W2 & $\begin{array}{l}\text { Cemented } \\
\text { carbide }\end{array}$ & - & - & - \\
\hline $\mathrm{C} 1$ & Cermet & - & - & - \\
\hline $\mathrm{C} 2$ & Cermet & - & - & - \\
\hline W3 & $\begin{array}{l}\text { Cemented } \\
\text { carbide }\end{array}$ & $\mathrm{TiN}$ & 2.0 & PVD \\
\hline W4 & $\begin{array}{l}\text { Cemented } \\
\text { carbide }\end{array}$ & $\mathrm{TiCN} / \mathrm{Al}_{2} \mathrm{O}_{3} / \mathrm{TiC}$ & 12.5 & CVD \\
\hline W5 & $\begin{array}{l}\text { Cemented } \\
\text { carbide }\end{array}$ & $\mathrm{TiCN} / \mathrm{Al}_{2} \mathrm{O}_{3} / \mathrm{TiN}$ & 8.0 & CVD \\
\hline $\mathrm{C} 3$ & Cermet & TiN/TiC/TiN & 5.0 & PVD \\
\hline
\end{tabular}

Microscopic examinations of the substrates and the coatings were made with a LEICA MEF4A light microscope. Cross-sectional fracture surfaces of the coatings were examined in a Philips XL-30 SEM. Secondary electron (SE) and the back scattered electron (BSE) images of the fracture surfaces were obtained at accelerating voltages in the range $15-20 \mathrm{kV}$.

Vickers micro-hardness was measured with a Shimadzu DUH 202 tester. A load of $70 \mathrm{mN}$ was used to reduce, to a large extent, the influence of the substrate material on the micro-hardness values of the coating.

The adhesion of the coatings to the substrates was tested using the scratch test, which is routinely used in the case of coatings obtained using PVD. Tests were carried out in the CSEM Revetest device with the following test conditions: load range $0-200 \mathrm{~N}$, load increase rate (dL/dt) $100 \mathrm{~N} / \mathrm{min}$, indenter speed (dx/dt) $10 \mathrm{~mm} / \mathrm{min}$, sensitivity of the acoustic emission detector AE 1.2.

The service performance of the coatings was evaluated from cutting tests carried out at room temperature. These tests, carried out with the cemented carbides and cermets, consisted of continuous dry turning of quenched and tempered C45E steel in a HH V630N lathe at $30 \mathrm{~kW}$ power rating. Multipoint SNMG 120408 (designation according to ISO 1832:1991) inserts were used for the continuous turning and these were fixed in a universal tool post to preserve the geometrical features of the cutting insert. The following parameters were used in the cutting tests: feed $\mathrm{f}=0.1 \mathrm{~mm} / \mathrm{rev}$, depth of cut $a_{p}=1 \mathrm{~mm}$, cutting speeds $\mathrm{v}_{\mathrm{c}}=250 ; 315 ; 400 \mathrm{~m} / \mathrm{min}$.

\section{Results and Discussion}

Using X-ray qualitative phase analysis it was shown that coatings containing the TiN type phase and, most probably, the complex TiAlSiN nitride phase formed on the surface of coated cemented carbides, as originally assumed, (Figure 1). Distinguishing the TiN and TiAlSiN phases using diffraction methods is impossible, due to their isomorphous nature. The TiAlSiN phase is the secondary solid solution based on TiN. Moreover, reflections from the cemented carbide substrate were found in the X-ray diffraction patterns, originating probably from the macro-particles deposited on the coating surface.

Scanning electron microscopic examinations of fracture surfaces revealed that the TiN/(Ti,Al,Si)N/TiN coatings deposited on the cermets and cemented carbides have a laminar packing. The TiN/ ( $\mathrm{Ti}, \mathrm{Al}, \mathrm{Si}) \mathrm{N}$ and $\mathrm{TiN}$ interlayers have a pore less structure and adhere well to each other, and the entire multi-layer coating adheres well to

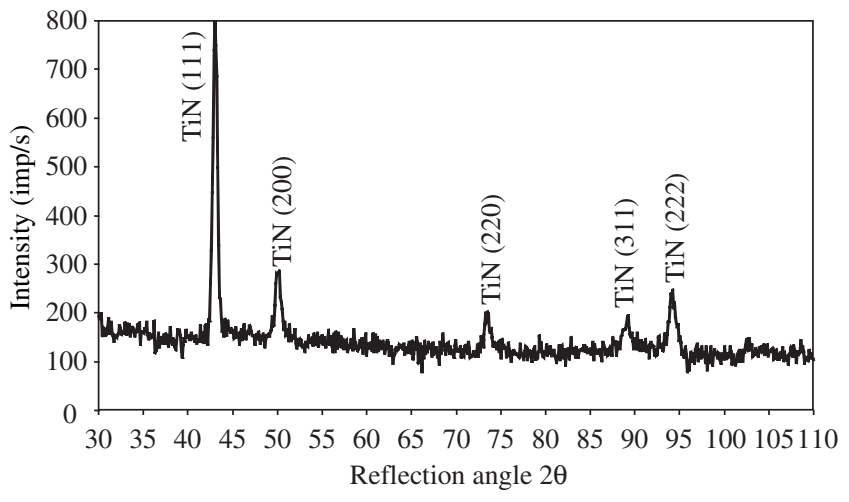

Figure 1. X-Ray diffractions pattern of the W1 type cemented carbides with the TiN/(Ti,Al,Si)N/TiN.

the substrate (Figure 2). The scanning electron microscopic examinations also revealed that the single and multi-layer coatings obtained by PVD or CVD processes were even on the commercial cemented carbide and cermet surfaces. The coatings were compact without visible pores and cracks and adhered well to the substrates (Figure 3). Only in the case of the single-layer TiN coating deposited using the PVD method on the W3 cemented carbide substrate, the coating thickness was uneven. The roughness of the coatings, defined by $\mathrm{R}_{\mathrm{a}}$ , was in the range $0.60-0.67 \mu \mathrm{m}$ and was significantly higher than that of the uncoated surface. The surface roughness parameter $\mathrm{R}_{\mathrm{a}}$ of the cermets and the cemented carbides were in the ranges $0.20-0.22 \mu \mathrm{m}$ and $0.35-0.36 \mu \mathrm{m}$ respectively. The increase in surface roughness that resulted with deposition of the $\mathrm{TiN} /(\mathrm{Ti}, \mathrm{Al}, \mathrm{Si}) \mathrm{N} / \mathrm{TiN}$ coatings can be attributed to the PVD process characteristics in the CAE mode, and the formation of characteristic micro-particles (Figure 4), due to deposition of pure titanium droplets from the sputtered disk, and the development of pits due to drop out of the titanium micro-particles immediately after the coating process. Hence the coating surfaces revealed heterogeneities that were droplet shaped and in the form of elongated micro-particles, that originated probably due to splattering on the substrate surface during coating deposition.

Deposition of the TiN/(Ti,Al,Si)N/TiN coating on cemented carbide and cermet substrates resulted in a significant increase in hardness of the surface layer, in the range $3100-3330 \mathrm{HV}_{0.07}$. The increase in hardness of the surface layer, compared to that of the uncoated substrate was about $40 \%$. Therefore, deposition of wear resistant coatings onto cermet and cemented carbide tool substrates results in a significant increase in microhardness of the surface layer, contributing to decrease in wear intensity of cutting tool flanks made from both, cemented carbides and cermets.

The TiN/(Ti,Al,Si)N/TiN coatings adhered very well to cemented carbide substrates and even better to cermet substrates, as shown in Table 2. The marked increase in adhesion of the coatings to the cermet substrates, as compared to the cemented carbide substrates, can be attributed to crystallization of the deposit by the plasma in the cathodic arc evaporation (CAE) mode. The substrate could have been the source of the active element in the PAPVD processes, as in the thermally activated processes (CVD). Failures in the TiN/(Ti,Al,Si)N/TiN coatings deposited onto the $\mathrm{W} 1$ and $\mathrm{W} 2$ type cemented carbides were mainly multiple two-sided coat chipping at the crevice edges, scratches and delamination inside the crevice, leading to local delamination of the coating at the end section where it is in contact with the crevice. Increase in load during the test resulted in increased chipping and joining of the craters in a "tooth-like" form at the crevice edges, leading to band-form type partial delamination of the coating. In the case of the TiN/(Ti,Al,Si)N/TiN coatings deposited on the $\mathrm{C} 1$ and $\mathrm{C} 2$ type cermets, another failure mode was observed. The first symptoms 


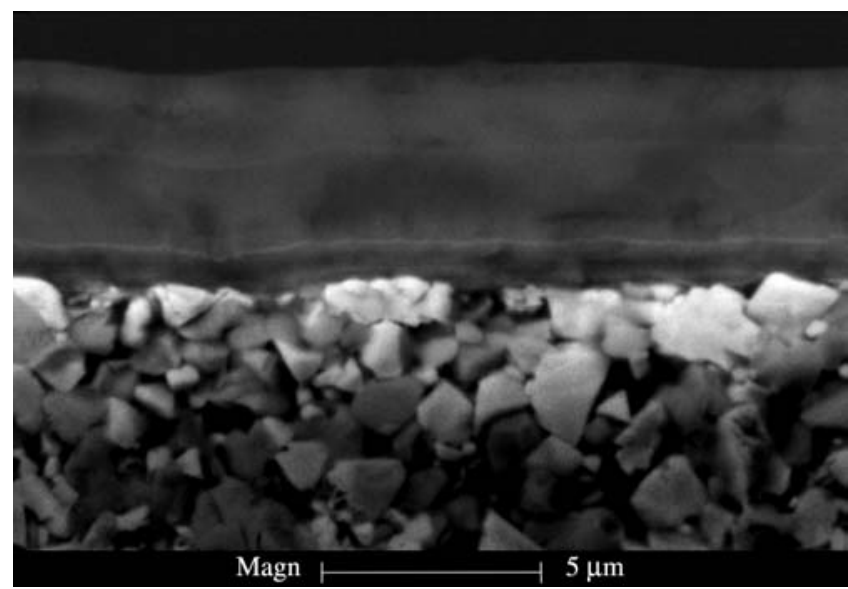

Figure 2. Fracture surface of the TiN/(Ti,Al,Si)N/TiN coating deposited on the W2 type cemented carbide surface.

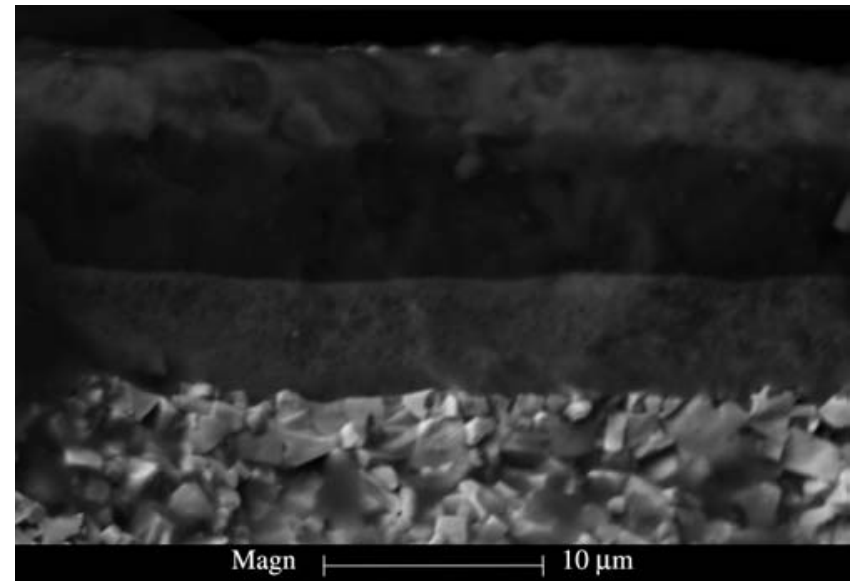

Figure 3. Fracture surface of the $\mathrm{TiCN} / \mathrm{Al}_{2} \mathrm{O}_{3} / \mathrm{TiC}$ coating deposited on the W4 type commercial cemented carbide surface.

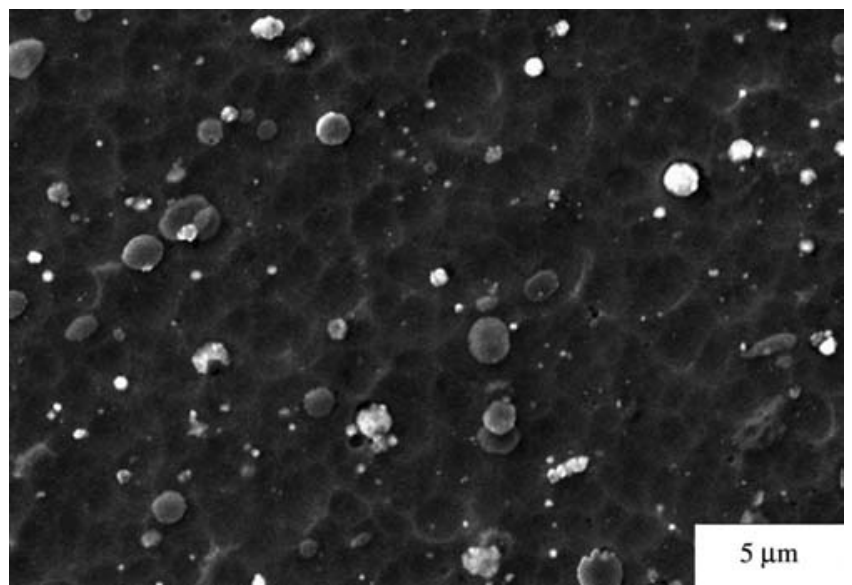

(a)

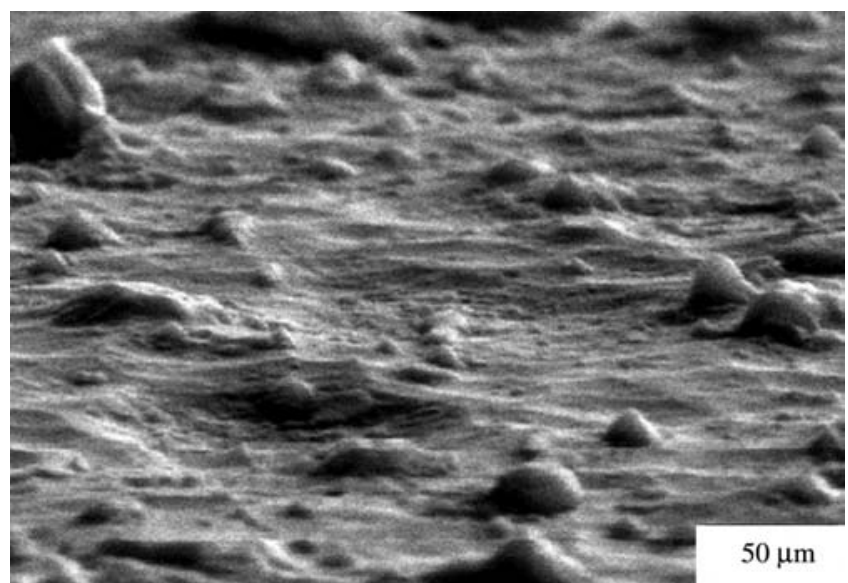

(b)

Figure 4. Topography of the $\mathrm{TiN} /(\mathrm{Ti}, \mathrm{Al}, \mathrm{Si}) \mathrm{N} / \mathrm{TiN}$ coating surface, deposited on the W2 type cemented carbide substrate.

Table 2. Comparison of properties of investigated cemented carbides and cermets.

\begin{tabular}{|c|c|c|c|c|}
\hline Material type + coating & $\begin{array}{c}\text { Microhardness } \\
\mathrm{HV}_{0.07}\end{array}$ & $\begin{array}{l}\text { Critical load } \\
\mathrm{L}_{\mathrm{C}}(\mathrm{AE})(\mathrm{N})\end{array}$ & $\begin{array}{l}\text { Tool life } \\
\mathrm{T} \text { (min) }\end{array}$ & $\begin{array}{c}\text { Roughness } \\
\mathrm{R}_{\mathrm{a}}(\mu \mathrm{m})\end{array}$ \\
\hline W1 uncoated & 1800 & - & 1 & 0.36 \\
\hline W2 uncoated & 1900 & - & 4 & 0.35 \\
\hline C1 uncoated & 2450 & - & 17 & 0.22 \\
\hline C2 uncoated & 2500 & - & 14 & 0.20 \\
\hline $\mathrm{W} 1+\mathrm{TiN} /(\mathrm{Ti}, \mathrm{Al}, \mathrm{Si}) \mathrm{N} / \mathrm{TiN}$ & 3100 & 57.20 & 20 & 0.65 \\
\hline $\mathrm{W} 2+\mathrm{TiN} /(\mathrm{Ti}, \mathrm{Al}, \mathrm{Si}) \mathrm{N} / \mathrm{TiN}$ & 3190 & 77.10 & 22 & 0.64 \\
\hline $\mathrm{C} 1+\mathrm{TiN} /(\mathrm{Ti}, \mathrm{Al}, \mathrm{Si}) \mathrm{N} / \mathrm{TiN}$ & 3310 & 131.20 & 55 & 0.60 \\
\hline $\mathrm{C} 2+\mathrm{TiN} /(\mathrm{Ti}, \mathrm{Al}, \mathrm{Si}) \mathrm{N} / \mathrm{TiN}$ & 3330 & 114.80 & 43 & 0.62 \\
\hline $\mathrm{W} 3+\mathrm{TiN}$ & 2000 & 49.61 & 8 & 0.59 \\
\hline $\mathrm{W} 4+\mathrm{TiCN} / \mathrm{Al}_{2} \mathrm{O}_{3} / \mathrm{TiC}$ & 2590 & 51.48 & 19 & 0.51 \\
\hline $\mathrm{W} 5+\mathrm{TiCN} / \mathrm{Al}_{2} \mathrm{O}_{3} / \mathrm{TiN}$ & 2300 & 77.58 & 22 & 0.60 \\
\hline $\mathrm{C} 3+\mathrm{TiN} / \mathrm{TiC} / \mathrm{TiN}$ & 3000 & 79.23 & 35 & 0.79 \\
\hline
\end{tabular}

of coating failure were the conformal cracks resulting from tension, which turned into isolated spallings at the bottom of the developing crevice and in the coating-crevice contact zone. Chipping and spalling failures developed in the central zones of the crevices and at its edges in the form of fine arc-shaped craters. Similar effects were observed at the edges in the end part of the crevice. Single failures are often connected, forming bands of local coating delamination. Along with the plastic strain of the substrate caused by the moving indenter, semicircles connected with conformal cracks occurred at the crevice bottom at higher loads indicating fragmentation, local delamination, 


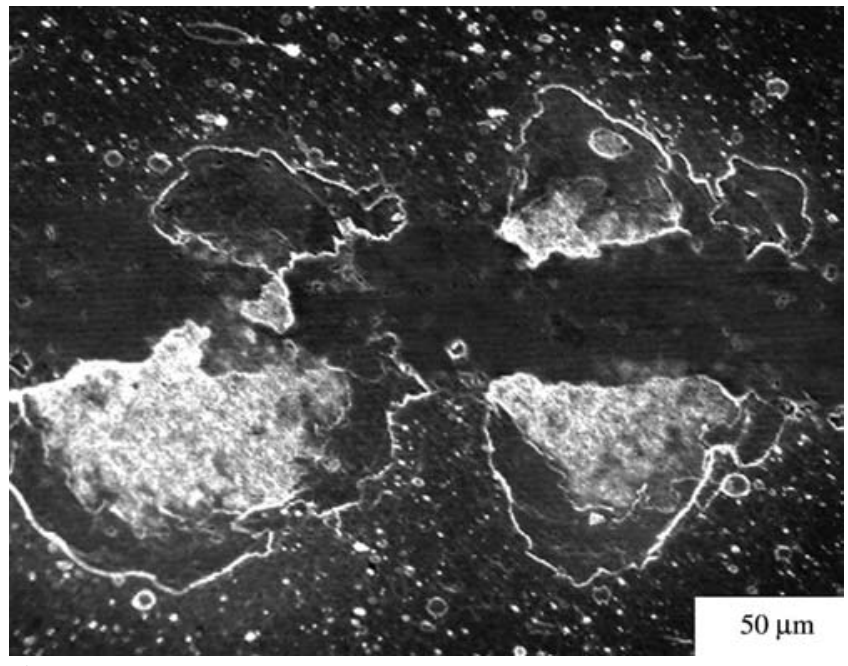

Figure 5. Defects characteristic of the TiN/ (Ti,Al,Si)N/TiN coating surface deposited onto the $\mathrm{W} 2$ type cemented carbide.

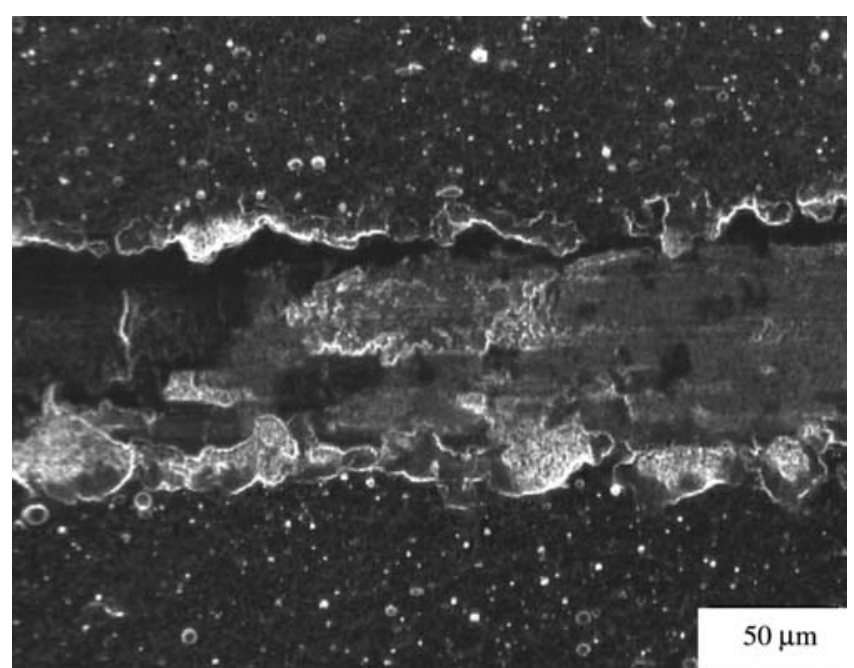

Figure 6. Defects characteristic of the TiN/ (Ti,Al,Si)N/TiN coating surface deposited onto the $\mathrm{C} 1$ type cermet.

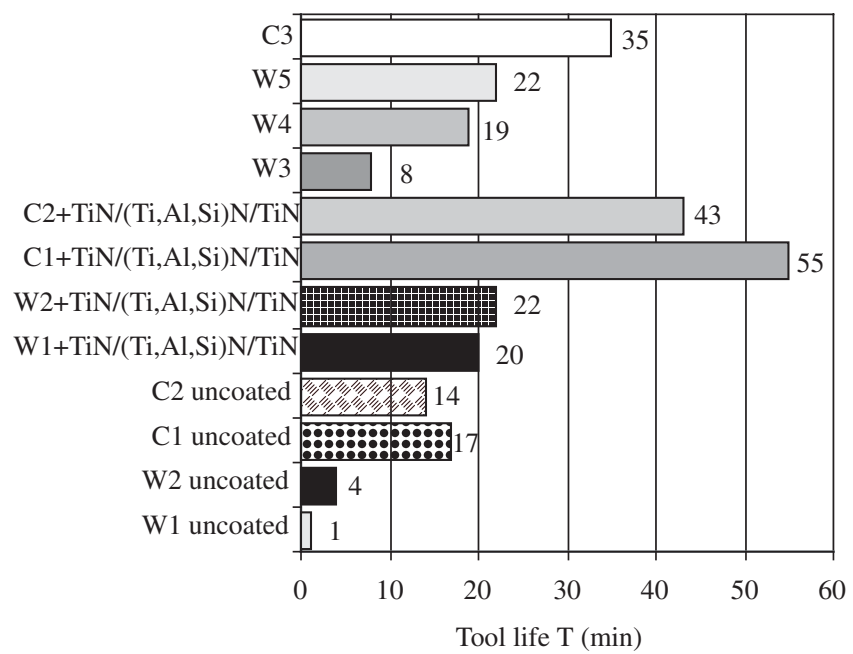

Figure 7. Comparison of tool life of tools made from cemented carbides and cermets with the TiN/ (Ti,Al,Si)N/TiN type coatings with commercially available tools. and consequent relocation of torn coating fragments. Figures 5 and 6 reveal defect characteristics of the coatings.

Correlations between hardness of the investigated materials and their service performance as multipoint inserts were made from single point turning tests. All the service tests results are comparative, i.e., the life of the inserts was determined based on wear land width measurements on the tool flank after machining, for similar turning parameters and for a predetermined period of time. Deposition of $\mathrm{TiN} /(\mathrm{Ti}, \mathrm{Al}, \mathrm{Si}) \mathrm{N} / \mathrm{TiN}$ wear resistant coatings on both cemented carbides and cermets resulted in increased wear resistance, and consequent increase in tool flank life (Figure 7). Therefore deposition of coatings on the investigated materials and consequent significant increase in microhardness of the surface layer resulted in reduced wear rate of tool flanks made from these tool materials. The best machined surface quality was obtained when machining was done with $\mathrm{C} 2$ type cermets coated with $\mathrm{TiN} /(\mathrm{Ti}, \mathrm{Al}, \mathrm{Si}) \mathrm{N} / \mathrm{TiN}$, whereas the worst machined surface quality was obtained upon machining with uncoated cemented carbide or cermet tools.

\section{Summary}

Coatings of the TiN/(Ti,Al,Si)N/TiN systems deposited using the PVD method in the CAE mode onto cermet and cemented carbide substrates demonstrated improved service properties compared to commercially available tool materials with single and multiple-layer, as well as single and double component coatings deposited using both the PVD or CVD processes. Cutting tests confirmed the advantages of the TiN/(Ti,Al,Si)N/TiN type coatings obtained with the PVD method in the CAE mode on cemented carbides and cermets, as a material with significantly reduced abrasive, thermal and adhesion wear, which has a direct influence on extending tool life, compared to wear of commercially available uncoated tools or tools with single and multi- layer coatings deposited by PVD/CVD methods.

\section{Acknowledgments}

This investigation was carried out partially in cooperation with Prof. J. Kopac and Prof. M. Sokoviæ from the Faculty of Mechanical Engineering of the University of Ljubljana (Slovenia), and also with Dr J. Holubar from SHM-Šumperk (Czech Republic). The investigations were partially financed within the framework of the Scientific and Technology Cooperation Joint Project "COAT-CUT" titled "New generation PVD coatings on tools for dry high speed cutting processes" between the Governments of the Republic of Poland and the Republic of Slovenia, headed by Prof. L.A. Dobrzañski and Prof. J. Kopac.

\section{References}

1. Dobrzański LA. Fundamentals of materials science and physical metallurgy. Engineering materials with the fundamentals of materials design. Warszawa: Wydawnictwo Naukowo-Techniczne; 2002.

2. Dobrzański LA, Golombek K, Kopac J, Sokovic M. Structure and properties of TiN/TiAlSiN/TiN PVD coatings on cemented carbides and cermets. Materials Science Forum. 2003; 437-438:41-44.

3. Dobrzański LA, Golombek K, Kopac J, Sokovic M. Proceedings of the Sixteenth Brasilian Congress of Mechanical Engineering COBEM; 2001 Nov 26-30; Uberlandia - Minas Gerais, Brasil. Uberlandia: The Federal University of Uberlandia; 2001. [CD-ROM].

4. Golombek K, Dobrzański L.A, Sokovic M. Properties of the wear resistant coatings deposited on the cemented carbides substrates in the cathodic arc evaporation process. Journal of Materials Processing Technology. 2004; 157-158:341-347.

5. Hogmark S, Hedenqvist P. Tribological characterization of thin, hard coatings. Wear. 1994; 179(1-2):147-154.

6. Navinsek B. Hard coating of cutting tools. Ljubljana: Institute of Jože Stefan; 1993. 